\title{
DRAMATURGIA E FALA
}

\section{Neyde Veneziano \\ Instituto de Artes/Unicamp e ECA /USP}

Recentemente assisti em Araraquara, uma cidade do interior paulista, a um espetáculo de uma tradicional companhia de circoteatro. Estavam levando, a cada noite, um drama (ou comédia) diferente. Como na boa tradição circense, os atores fizeram, primeiro, uma pesquisa sobre a cidade. Informaram-se sobre a história, sobre a política, sobre os comerciantes, sobre os fatos recentes. Procuraram saber se havia, ali, algum "palacete de rico" (porque se houvesse, pela lógica popular, haveria alguém que explorou os pobres). O drama a que assisti não foi lido, nem analisado, nem decorado. Foi transmitido oralmente. Nenhum dos atores sabia o nome do autor. Denominava-se "Índia", o tal drama. No final, mostraram-me outros trechos de uma peça que se chamava "A mulher que veio de Londres". E cada um dos componentes do elenco sabia o seu "papel", que é muito mais do que um personagem. É uma função dramática: "o vilão", "o galã", "a dama-galã", "a caricata", "o tonto". Todos conheciam os roteiros dos espetáculos, as sequiências das cenas. Mas, de acordo com a realidade e com os fatos locais, muita coisa ia sendo mudada. Pois, no circoteatro, uma sessão nunca é igual à outra. E em cada cidade, a mesma história resulta num espetáculo totalmente diferente. Este é um procedimento normal, oriundo do teatro de convenções, que é próprio de todo o teatro mambembe, próprio da estética popular, oriunda da Commedia dell'arte, por sua vez proveniente das Atelanas e que, talvez, tenha vindo dos mimos gregos e das comédias de Mégara.

$\mathrm{O}$ circo e seus remotos ancestrais estiveram sempre ligados à cultura popular e à arte de fazer rir. A rigor, é muito difícil precisar a data e origem dos espetáculos em recintos fechados ou abertos, que marcaram o surgimento do gênero. A vontade de divertir foi inventando, durante séculos, feiras populares, barracas exibindo fenômenos, habilidades extravagantes, truques mágicos e malabarismos. O circo, cujas remotas raízes estão nos espetáculos 
populares dos gregos e dos romanos, apossou-se das criações de palhaços da comédia popular e da Commedia dell'Arte.

Alguns poucos trabalhos universitários já abordaram, de forma tangencial, a questão da arte da encenação e da interpretação no circo brasileiro. Fora dos meios acadêmicos, porém, é muito comum encontrarmos artigos, entrevistas, crônicas, depoimentos (mesmo fora do país), cujos discursos nos fazem crer que existe um jeito brasileiro de fazer circo (principalmente o circo-teatro), uma forma de interpretação que traduz um tipo determinado de caráter. E que este jeito brasileiro estaria combinado a uma certa descontração capaz de proporcionar um terreno fértil para a criatividade e a espontaneidade. Nada poderia se apresentar de forma menos científica ou menos rigorosa. Um tenaz preconceito acredita que a espontaneidade e a criatividade não se misturariam a técnicas e procedimentos, se colocados no mesmo cadinho.

Ao se estudarem o circo, as bufonarias e os diversos meios de expressão populares, tem-se estudado as formas e os conteúdos, sem um mergulho nos processos de elaboração. Pensam-se nos enunciados, não nas formas de enunciação.

Falta, também, um estudo mais aprofundado do chamado "teatro de convenções" e de como ele chegou até nós. Certamente, a Commedia dell'arte plasmou uma estrutura que se tornou rígida para o teatro francês e que, mais tarde, retornaria afrancesada para a Itália como "teatro de convenções", no qual espera-se a "tirada" do capocomico, a esperteza da "primeira atriz", a gag do "bufão", tudo como manda o figurino do teatro all'improviso.

Todas as formas dramáticas reconhecem, como primeira e unitária origem, o rito: nasceram com os momentos essenciais e mais significativos das cerimônias religiosas. Também a comédia e, em geral, aquilo que se chama de teatro profano, teve na sua ascendência características do sagrado, ainda que este sagrado pertencesse ao mundo ritualístico das religiões pagãs. Este teatro profano de origem sagrada sobreviveu durante todo o período de perseguições ao teatro, profissionalizou-se nas ruas de Veneza e se instalou nas elegantes salas de nossos dias. A oralidade geradora destas manifestações, sob todas as suas formas, determinou uma estética popular e um jeito de representar direta e exclusivamente para o público. 
O espírito classificador dos gregos já qualificava a tragédia como forma literária das mais apreciadas. Sobre a natureza literária da dramaturgia, perguntas, no entanto, continuam desafiando o Ocidente pensante: Haverá mesmo diferenças significativas entre dramaturgia popular e dramaturgia elitista? Literatura dramática é somente aquela que exige o exercício solitário "em gabinete", ou também se cria literatura diretamente sobre a cena? E o público? É criador ou, apenas, espectador? As questões deslizam, umas sobre as outras.

Desde Aristóteles especialistas se ocuparam do caso. Estudos e pesquisas desvelaram as técnicas dramatúrgicas. Todos foram unânimes: dramaturgia se apóia sobretudo na "ação dramática"1 e também nos conflitos, na superação dos obstáculos, na manipulação das situações. Há arquiteturas muito claras para os diversos subgêneros da literatura dramática. Tratam-se de estruturas que descendem da tragédia ou da comédia nova ou do drama romântico. No arcabouço de cada gênero há o lugar certo para que um velho tio (ou médico da família, ou advogado do casal) entre para dar um conselho como porta-voz do autor, por exemplo. Há também o espaço ideal para que casais enamorados atinjam seus objetivos, criados brejeiros compliquem a vida de seus patrões, heróis incorruptíveis vençam as dificuldades ${ }^{2}$. No clássico edifício dramático, há princípios como "nós", "complicações", "desfecho". Maleáveis e flexíveis aos tempos, estas construções se adaptaram aos estilos, às escolas, aos pensamentos filosóficos e estéticos de cada período.

Numa classificação mais exclusiva, é apropriado lembrar que, independente de épocas ou estilos, o gênero dramático comporta as

1 Ação dramática, a meu ver, é uma expressão redundante, já que drama quer dizer ação.

2 A Commedia dell'Arte tinha 4 tipos-fixos principais: o "Velho" (nos subtipos Magnifico e Dottore), representando a condição, definitiva e irreversível, da velhice, do "ser velho"; os "Enamorados" (homem e mulher, nas variantes ingênuo e aventuroso) representam a condição de "quem ama" e devem lutar para merecer, enfim, coroarem o seu sonho, "projeto de amor"; O "Servo" (no desdobramento de $1^{\circ}$ e $2^{\circ}$ e na versão feminina Servetta) representa, entre a função dramática ambivalente de fazer-e-desfazer, a eterna "luta pela sobrevivência"; e o "Capitão" (o covarde com máscara de valente) representando o conflito interior entre "ser e parecer". Cada um desses personagens tinha o seu projeto muito claro. 
três posturas que lhe são condizentes: o dramático-épico (teatro narrativo), o dramático lírico (em que a poesia compete com a ação) e o dramático-dramático, ou seja, aquele em que se trata, exclusivamente, do aqui e agora.

Hoje, estuda-se, também, a dramaturgia do ator, a dramaturgia do espetáculo e até o teatro da não-dramaturgia. Não nos cabe aqui a discussão destas terminologias. ${ }^{3}$ Voltemos, portanto, ao teatro brasileiro e verifiquemos como e em que medida aqueles atores que improvisam estariam, ou não, com suas "falas", fazendo literatura dramática.

Pesquisar o espetáculo ou o passado da cena brasileira é trabalhar em ausência, pois o objeto de estudo não pode ser recomposto. Há problemas encontrados pelo artista, enquanto representa, que dificilmente poderão ser compreendidos distantes da experiência concreta.

O centro de minhas pesquisas anteriores constituiu-se no levantamento das convenções e dos procedimentos dramatúrgicos do teatro de revista brasileiro, tomando este gênero como emblemático. Busquei as estruturas importadas e as comparei aos modelos brasileiros. Verifiquei significativas diferenças. A partir daí, desviei o olhar para o lado espetacular desse nosso passado teatral.

Tornar orgânica a dialética entre dois pólos, dramaturgia e cena contemporânea, a fim de que se possam nutrir um do outro, transformou-se em uma constante preocupação. A aplicação de metodologias importadas à observação de nossos processos, criativos e à recuperação de uma estética anterior, como determinante da atual, dificultou de início o entendimento desta cena que parecia anêmica, sem tessitura. Que parecia contrafação.

Os textos abordados apontavam para um perfil peculiar do teatro no país delineando gêneros que se casaram com ritmos, assuntos e fala brasileiros. Este perfil, calcado em técnicas codificadas durante longo tempo, denotava haver procedimentos próprios e um sistema de códigos através dos quais tipos brasileiros falavam e agiam em cena, comprometidos com as platéias de seu tempo.

Remeto a Patrice PAVIS. Dicionário de Teatro. Trad. Jacob Guinsburg e Maria Lúcia Percira. São Paulo: Perspectiva, 1999. 
Através de ajustes e combinações, chegamos aos procedimentos da construção da cena, da construção dos personagens-tipo e a uma consequiente fala brasileira.

À tradição do teatro de texto da cultura européia, paralelamente, inscrevia-se a dramaturgia do ator brasileiro, que tinha a ver com a construção da sua parte no espetáculo, com todo o seu processo criativo como intérprete de tipos e com uma grande dose de improvisação com a qual ele personalizava a técnica.

Quanto à dramaturgia propriamente dita, a par das estruturas importadas, revelaram-se estruturas peculiares, inoculadas pelos nossos ritmos (ritmos estes que podem ser musicais, ou de falar, de caminhar, de viver) e determinadas pela natureza transgressora do riso carnavalesco. Chegamos a um formato brasileiro de teatro diferente e único. Da transmigração e das combinações entre o material fornecido pelos atores e as influências estrangeiras, germinou o modelo nacional.

Do comprometimento entre estruturas e cena, entre atores e seu público, verificou-se uma dramaturgia pensada como texto de representação, por vezes fragmentada entre texto falado e musicado, pois escrever para teatro era, também, escrever para uma determinada companhia submetida a uma hierarquia (a do teatro de convenções), com atores treinados para o improviso e especializados na construção de tipos, bem ao contrário da atividade isolada que é a dramaturgia de gabinete.

Personagens construídos por atores que elegiam um certo jeito de falar, um certo modo de mover-se, um modo de caminhar, uma certa qualidade de energia, um claro tipo capaz de manter consistência e reconhecimento em diferentes contextos entrelaçaram-se para se tornarem textura: texto.

Texto que abria espaços para improvisações e se utilizava destes tipos, mais máscaras do que propriamente personagens, os quais podem ser tomados como uma pré-partitura, elástica. No outro extremo, como fruto de trabalho "pensante" e não vivenciado, estaria o "grande" personagem, tradição do teatro de texto da cultura clássica tradicional.

Esta dramaturgia brasileira, do autor e do ator ou para o ator, tem a ver não só com a tradição popular daquele que conhece as leis 
do jogo, mas também com a construção das diversas partes do espetáculo, como um conjunto polifônico de vozes independentes a serviço de uma única obra: o espetáculo.

Ao examinar os conteúdos destas peças verifiquei como estes conteúdos foram codificados e estetizados pelos atores e lidos pela platéia de seu tempo. Detive-me, não só na forma dramatúrgica, mas nos elementos que delinearam o perfil deste gênero popular de teatro no pais, repleto de tipos brasileiros, ritmos brasileiros e, sobretudo, com a fala brasileira.

Já são conhecidas as diferenças entre as expressões técnicas "texto" e "texto espetacular". Contudo, cabe aqui recordar que ao conjunto de todos os elementos previsíveis que entram na composição do objeto de arte denominado espetáculo chama-se "texto espetacular".

Dentre as tantas partes que compõem o espetáculo teatral (a direção, o espaço cênico, a cenografia, os figurinos, a sonoplastia, a iluminação), nenhuma é mais, ou menos importante. É no ator, entretanto, que reside a essência do teatro. Ele é o centro das atenções e o espetáculo só se realiza quando um ator, no palco, torna presente (re-apresenta > representa) um papel que já existe (pois foi criado no passado). Dramaturgia, portanto, é texto dramático. Não é teatro enquanto o texto não tiver sido encenado. E ao ator compete, ao interpretar, dizer este texto.

Seja na estética popular, da qual nos ocupamos acima, seja trabalhando sobre textos que comportam uma dramaturgia mais rígida e menos elástica, será, sobretudo, da fala do ator que surgirão, diante do público, as situações que vão impulsionar a ação.

Em dramaturgia as partes do diálogo ditas por cada um dos personagens são denominadas "falas". Em cena, os atores também "falam". É natural, portanto, que a dramaturgia na construção das "falas" se aposse dos dispositivos próprios da oralidade.

Em períodos "preciosísticos", conseqüentes do Renascimento e da sublimação das artes, o dramaturgo, então considerado "poeta", recusava a linguagem cotidiana. Reproduzir a simplicidade do dia-adia seria banalizar a arte, fazer um teatro menor. Ao mesmo tempo, nas ruas, o povo continuava cantando, continuava esbravejando em ritmo grosseiro ou dizendo, em acentos adocicados, coisas igualmente importantes àquelas que mereceriam destaque na cena dos nobres $\mathrm{e}$ 
prestigiados. O povo sabe dizer coisas profundas e complexas com grande simplicidade.

O teatro do povo, aquele que sobrevivia pela mão do ator, opunha-se declaradamente ao teatro de elite. Este, sim, era considerado "literatura". Este, sim, era sublime. E ao sublime não era permitido "roubar" as coisas do povo. E a dramaturgia-literatura caminhou paralela àquela das praças, das estalagens, dos tablados montados ao ar livre. O poeta (feito dramaturgo) buscava a "fala" ideal, a beleza da expressão. Diseurs e diseuses foram consagrados nas cenas que mereceram titulo de obra artística. Não caberia aqui uma exposição retrospectiva da história teatral. A trajetória estética desta arte desvela o "faz e desfaz" de regras, manifestos, leis, vanguardas.

Se pudéssemos rotular arte da dramaturgia, organizá-la em gavetas, veríamos que as gavetas da arte popular mostravam-se repletas de linguagem viva, de falas verdadeiras, de brincadeiras e de jogos que não eram considerados material artístico nem científico. Enquanto isso, do outro lado do armário, prateleiras roubavam, aos poucos, para a pomposa arte dramática, falas e situações da dramaturgia feita e pensada diretamente sobre a cena.

Molière e Goldoni foram os autores paradigmáticos destes honrados "furtos". Molière roubou a arte das ruas, experimentou as técnicas da Commedia dell'arte e fez delas uma grande literatura.

Goldoni, o advogado veneziano, reformou o teatro italiano à procura do "verdadeiro". Tomou as estruturas da Commedia dell'arte, matou as máscaras e fixou-se na verossimilhança. Por máscara, Goldoni entendeu "tipo fixo" e preocupou-se em lhes dar unidade psicológica. Não tratou os Enamorados como "tipos fixos", mas como "caracteres" (não arquetípicos) semelhantes ao ser humano, individualizados em detalhes. Plasmou-se o modelo do "teatro de convenções", um teatro popular que subia aos palcos tradicionais, agora não mais propriedade exclusiva das ruas. E vieram os chamados "dramaturgos profissionais". Nesta lógica inscreveu-se grande parte do teatro brasileiro. São desta geração Gastão Tojeiro, Abadie Faria Rosa, Armando Gonzaga, Cláudio de Souza. Autores que criaram comédias "de encomenda" para um determinado elenco, pautado pela experimentada estrutura organizacional, com capocomico, primeira atriz, soubrette, ingênua, galã. Esta dramaturgia abria espaços para os improvisos, para as "tiradas", para os "cacos" somente permitidos aos primeiros atores e 
proprietários da companhia teatral. Copiando as estruturas das ruas, este teatro estava, novamente, engessado. Procurava a "fala bela" ao mesmo tempo em que a desalentava.

O teatro moderno é moderno porque foi capaz de olhar o popular e redefinir seus modelos. Hoje, desmanchou-se a linha que dividia a estética erudita daquela popular. Inflacionou-se a literatura com as falas do povo. À compreensão de Nelson Rodrigues, quando uma vizinha reproduz o som brasileiro com "Obrigada, ouviu?", responde o metaplasmo de Carlos Alberto Soffredini: "Bregada, viu?". Um som de fala brasileira que se instala na literatura pelas mãos de hábeis dramaturgos.

Volto a Dario Fo e ressalto que ele é casado com Franca Rame, uma figlia d'arte. Ser figlio d'arte, na Itália, significa ter nobres antepassados. Significa pertencer a uma famiglia d'arte, uma família que pode se orgulhar de descender, diretamente, da Commedia dell'arte, organizada com intérpretes de tipos-fixos. Há, ainda, algumas famiglie d'arte preservando vivas as tradições. A Famiglia Rame é uma delas. Na boa tradição do teatro itinerante, quando chegam a uma cidade, os atores fazem uma pesquisa. Informam-se sobre a história, sobre a política, sobre os comerciantes, sobre os fatos recentes. Procuram saber se há algum castelo (porque se houver, pela lógica popular, há alguém explorando os pobres). O drama que apresentam não foi escrito. Foi transmitido oralmente. Nem foi decorado. Cada um dos atores conhece uma infinidade de diálogos apropriados que, naturalmente, variam para cada ocasião e, principalmente, os assuntos e mecanismos da dramaturgia feita por aqueles que conhecem jogos de encaixe e equívocos, travestimentos e reviravoltas, abertura e desfecho, frases e gestos convencionais que advertem os outros intérpretes sobre mudanças de situações ou sobre a aproximação de um final de quadro, de ato ou de espetáculo.

Muitos perguntam por que Dario ganhou o Nobel de Literatura, uma vez que Dario é, antes de tudo, um ator. Um crítico americano respondeu: "Talvez porque ele tenha encontrado a forma de injetar a energia do ator na linguagem escrita." ${ }^{4}$

Volto ao pequeno circo-teatro que vi em Araraquara...

4 Declaração de um critico americano não identificado, no vídeo $A$ Nobel for two (acervo da Companhia Fo e Rame). 


\section{Referências Bibliográficas}

DUCHARTRE, Pierre Louis. La commedia dell'arte. Paris: Librairie Théâtrale, 1955.

FAVA, Antonio. La maschera comica nella commedia dell'arte. Milão: Endromeda Editrice, 1999.

FAVA, Antonio. Dario Fo, Teatro. Organizado por Franca Rame. Turino: Einaudi, 2000. 1242 p. il. (Collana Millenni).

MELDOLESI, Claudio e TAVIANI, Ferdinando. Teatro e spettacolo nel primo ottocento. Roma: Bari/Laterza, 1995.

PANDOLFI, Vito. Regia e registi nel teatro moderno. Bolonha: Universale Capelli, 1973.

PAVIS, Patrice. Dicionário de Teatro. Trad. Jacob Guinsburg e Maria Lúcia Pereira. São Paulo: Perspectiva, 1999.

PROPP, Vladímir. Comicidade e riso. São Paulo: Ática, 1992.

TAVIANI, Ferdinando. La commedia dell'arte e la società barocca: la fascinazione del teatro. Roma: Bulzoni, 1991.

VENEZIANO, Neyde. Não adianta chorar: teatro de revista brasileiro ... Oba! Campinas: Ed. Unicamp, 1996.

VENEZIANO, Neyde. O teatro de revista no Brasil: dramaturgia e convenções. Campinas: Ed. Unicamp, 1991.

ZUMTHOR, Paul. A Letra e a voz: a "literatura" medieval. São Paulo: Companhia das Letras, 1993.

ZUMTHOR, Paul. Performance, recepção, leitura. Tradução Jerusa Pires Ferreira e Suely Fenerich. São Paulo: EDUC, 2000. 